\title{
AGENTE DEL REY Y REFORMADOR DEL REINO: LA ACTIVIDAD DEL II CONDE DE CASTRILLO EN NAVARRA (1629-1630)
}

\author{
Marcelo Paulo Correa \\ (CONICET/U. Nacional de Salta, Argentina)
}

\section{RESUMEN}

Durante los años 1629 y 1630 el conde de Castrillo fue enviado al reino de Navarra a implementar un conjunto de transformaciones que tenían por objetivo la mejora en la recaudación del reino. Esta misión se enmarcó en un grupo de medidas emprendidas en la época del conde duque de Olivares para dar respuesta a la necesidad de gasto que implicaba la política belicista.

El estudio de los conflictos desatados por las tentativas de reforma permite observar las estrategias y representaciones de los distintos actores sobre la relación reino-monarquía. De igual manera, la documentación refleja un momento de consolidación de Castrillo como agente de Felipe IV.

PALABRAS CLAVE: Navarra; Castrillo; Felipe IV; Olivares; Reforma

\section{KING'S AGENT AND REFORMER OF THE KINGDOM: THE WORK OF THE II COUNT OF CASTRILLO IN NAVARRA (1629-1630)}

\begin{abstract}
Between 1629 and 1630, the count of Castrillo was sent to Navarra to implement a set of transformations that aimed to improving the kingdom's revenues. This mission was conducted as part of a group of measures taken during the ministry of the count-duke of Olivares to meet the spending needs that the warmongering policy produced.

The study of the conflicts caused by the attempts of reform allows for analyzing the strategies and representations of the different participants in the kingdom-Crown relationship. Similarly, the documents show a the consolidation of Castrillo's role as Philip IV's agent.
\end{abstract}

KEY WORDS: Navarra; Castrillo; Philip IV; Olivares; Reform 


\section{INTRODUCCIÓN}

Durante el valimiento de Olivares las medidas hacendísticas llevadas adelante para solventar el gasto bélico obligaron a implementar reformas o modificaciones en la relación con los reinos. Si bien hoy aquella época ha vuelto a estar en el foco de debates historiográficos, los estudios recientes muestran que diversos agentes de la Monarquía fueron enviados a los reinos que la componían para llevar adelante las negociaciones. En ese contexto, García de Avellaneda y Haro, II conde de Castrillo, fue asignado al reino de Navarra.

En el presente artículo se analizarán los efectos políticos que tuvieron las acciones que llevó adelante. Al mismo tiempo se estudiará el impacto que tuvo sobre su carrera en el servicio de la Monarquía de Felipe IV.

Para dimensionar la visita de Castrillo es preciso considerar que la conquista del reino de Navarra en 1512 fue el hecho fundacional de su incorporación a la corona de Castilla en tiempos de Fernando el Católico, acontecimiento que se transformó en uno de los componentes de su identidad política a lo largo de toda la Edad Moderna, por lo cual pasó al conglomerado heredado por la dinastía de los Austrias. En efecto, el elemento característico de este reino en su agregación a la Monarquía de los Austrias fue la existencia de una combinación de elementos propios del sistema de conquista y la pervivencia de sistemas de gobierno regnícolas.

Ahora bien, Navarra tenía algunas particularidades en su relación con la Corte de Madrid. En principio, no existía en Madrid un consejo que representara al rey en el reino, lo cual creaba una situación diferencial ya que su Consejo Real permaneció en Pamplona ${ }^{1}$. Por otro lado, el reino se situaba en el concierto de la Monarquía como un "reino conquistado", situación que implicaba un desafuero incompleto.

Como bien explica el profesor Alfredo Floristán, hasta 1628 la recaudación sobre Navarra se había mantenido más o menos estable, es más, durante el siglo XVI el crecimiento poblacional estuvo muy vinculado a este aumento fiscal ${ }^{2}$. En efecto hasta ese momento los monarcas de la dinastía Habsburgo, incluido Felipe IV, sólo habían pedido a Navarra la defensa de las fronteras.

Resulta llamativa la forma en la que Felipe IV y sus predecesores respetaron los privilegios de este reino, respondiendo a los reclamos de sus Estados generales cuando estos rechazaban alguna novedad en la gobernanza regnícola. Sin embargo, hacia 1628 la situación se vio modificada en medio de los conflictos creados por la Guerra de los Treinta años.

Según el profesor Domínguez Ortiz, hasta 1627 las finanzas de la Monarquía no habían enfrentado problemas "novedosos", es decir que la mayoría de ellos provenía de una herencia consuetudinaria del manejo de la economía, también se señala que muchos de los problemas de los primeros momentos del reinado de Felipe IV eran fruto del mal manejo de las finanzas de su predecesor. Es decir, que la

${ }^{1}$ Alfredo Floristán Imízcoz, El Reino de Navarra y la conformación politica de España (1512-1841) (Madrid: Akal, 2014), 5-20.

${ }^{2}$ Ibídem. 
política lermista signada por el pacifismo no necesariamente implicó un descenso del gasto, situación que profundizó la inestabilidad de la Hacienda Real. Sin embargo, la primera bancarrota del reinado dejó en claro que las dificultades para conseguir recursos aumentaban en un contexto de belicismo ascendente ${ }^{3}$.

Es por ello que la suspensión de pagos a los asentistas de Felipe IV de ese momento fue provocada por el agotamiento castellano, situación que limitó la capacidad extractiva de la Corona. Debido a que la bancarrota significaba una ruptura - por lo menos temporal - con los asentistas, la Corona había buscado una posible salida en los llamados 12 millones, es decir en una recaudación extraordinaria ${ }^{4}$ lo cual da cuenta de que la Hacienda generaba soluciones en la medida en que se presentaban los problemas de financiamiento.

Hablamos de "ruptura temporal" en base a las afirmaciones del profesor De Carlos Morales, quien ha explicado que luego de la bancarrota los asentistas genoveses buscaron rápidamente volver al vínculo con Madrid. Entonces es parcialmente cierto que la crisis de 1627 obligó a la Corona a buscar nuevas formas de financiamiento. En respuesta a esa inestabilidad, el Conde-Duque gestaba un proyecto de extensión del área de mayor contribución, en la cual los reinos extracastellanos de la Monarquía debían ocupar un papel central; veremos con el caso de Navarra como esa necesidad terminó transformando la relación entre el rey y sus súbditos.

Poco antes de la llegada de García de Avellaneda y Haro a Navarra para la ejecución de las reformas tributarias se había percibido y descubierto desde Madrid cierta falta de control sobre las recaudaciones aduaneras y también la profunda imbricación entre virreyes, Consejo y nobleza local en los asuntos financieros ${ }^{5}$. Esta situación parece haber generado cierta falta de confianza en la administración local o en todo caso sirvió como pretexto para ejecutar las reformas necesarias. Sobre todo, si se tiene en cuenta que la palabra reforma en general iba unida a una visión moral del ejercicio político que en la práctica derivaba en un recambio de personas vinculadas a una u otra función política.

En ese contexto se inserta la misión encomendada a García de Avellaneda y Haro, conde consorte de Castrillo desde 1629 por su matrimonio con María de Avellaneda, nieta del virrey navarro Bernardino de Avellaneda (1623-1629), quién falleció poco antes de las acciones llevadas adelante por García de Haro en el reino pirenaico.

Dicha vinculación familiar con María de Avellaneda y su estancia en Navarra para pactar las condiciones del matrimonio le permitieron conocer mejor la situación en el reino y es probable que por esa causa el valido le encomendara la tarea de revisar la recaudación en el reino, con lo cual se buscó una reforma de la cámara de Comptos y también obtener nuevos donativos para la Corona.

\footnotetext{
3 Antonio Domínguez Ortiz, Politica y Hacienda de Felipe IV (Madrid: Editorial de Derecho Financiero, 1960), 3-17.

${ }^{4}$ Carlos de Carlos Morales, "Olivares y los banqueros de Felipe IV. La crisis financiera de 1627”, Libros de la Corte.es 2 (2010): 9-15.

${ }^{5}$ Floristán, El Reino de Navarra, 185.
} 


\section{CASTRILLO Y LAS REFORMAS EN NAVARRA}

La condición previa para garantizar buenos resultados en el asunto de Navarra implicaba dotar de un poder extraordinario a Castrillo para poder actuar sobre las instituciones tradicionales del reino irrumpiendo en sus usos consuetudinarios y su funcionamiento enraizado en antiguas legislaciones confirmadas a lo largo del siglo XVI. Es por ello que la comisión pasó por encima del virrey y del consejo real ${ }^{6}$.

Las acciones que el enviado llevó adelante en la primera parte de su visita tenían como espacio de actuación a la Cámara de Comptos, organismo fiscal por excelencia de la Monarquía navarra desde antes de su adhesión a Castilla en tiempos de Fernando el Católico?.

Hacia 1630 Felipe IV delegaba una serie de atribuciones en Castrillo y justificaba su decisión ante los miembros de le Cámara de Comptos diciendo: "Por averse dudado en diferentes partidas, cometi el examen de ellas, y de lo que fuesse necesario prevenir en lo de adelante" 8 .

La primera de las órdenes rompía con el entramado "institucional" de la Monarquía. En principio por las preeminencias que las autoridades virreinales tenían por ejercer la representación del rey en las distintas partes del cuerpo político de la Monarquía Hispana y en segundo lugar porque la existencia de la cámara era anterior a toda reforma, de este modo se aseguraba de algún modo el cumplimiento de las ordenanzas de Felipe IV.

Esta situación quebraba entonces con la tradicional política de gobierno a través de los virreyes designados en condición de realeza. Un modelo de gobierno que se había inaugurado en 1512, cuando se dispuso el mantenimiento del Consejo Real y los oficios de la casa y Corte de Navarra?.

Por otro lado, las ordenanzas tenían la intención de regularizar la recaudación a través de la promoción del registro de cuentas, el cual debía ser utilizado con mayor rigurosidad. Además de ello el Rey confirmaba la preeminencia del Consejo de Órdenes ante las situaciones dudosas referidas a la concesión de mercedes reales, apartando otro tipo de vínculos que pudiesen no ser convenientes para la relación rey-reino.

Del mismo modo, el conde de Castrillo ponía especial atención en la concesión de privilegios y la administración de las mercedes, para ello hacía énfasis en el procedimiento que se debía seguir respecto de las consultas sobre los mismos ${ }^{10}$. Situación que implicaba un necesario recambio en las elites vinculadas a la Monarquía,

\footnotetext{
${ }^{6}$ María Isabel Ostolaza Elizondo, "La Hacienda Real en Navarra durante la etapa de los Austrias", Principe de Viana, 240 (2007), p. 246.

${ }^{7}$ Cfr. María Narbona Cárceles, La Corte de Carlos III el noble, Rey de Navarra (Pamplona: EUNSA, 2006).

${ }^{8}$ Archivo General del Reino de Navarra (en adelante AGRN), CO_PS1 ${ }^{a}$, Leg. 4, No 29.

${ }^{9}$ Manuel Rivero Rodríguez, La Edad de Oro de los virreyes. El virreinato en la Monarquía Hispánica durante los siglos XVI y XVII (Madrid: Akal, 201), 44. En especial cita 48.

${ }^{10}$ Ibídem.
} 
cuyos efectos explican la insistencia de los reclamos por los abusos cometidos por el emisario del rey durante su visita a Navarra.

En definitiva, las transformaciones impulsadas en la Cámara de Comptos eran señaladas por sus detractores como actividades para la alteración de un orden consuetudinario, mientras que para quienes las defendían (entre ellos el rey como veremos a continuación) se trataba de medidas que obligaban a volver al orden ciertas alteraciones recientes en la recaudación de tributos para el rey en Navarra.

En ese sentido hay que decir que los reclamos ante el Consejo de Órdenes y ante Felipe IV tenían otro tipo de matiz. A saber, en 1630 la Cámara de Castilla informaba sobre quejas referentes a acciones del conde de Castrillo tocantes a ese órgano colegiado de la Monarquía y no al Consejo Real navarro refería a asuntos de "gobierno y justicia".

De este modo la Cámara de Castilla informaba que:

[..]siendo así que el memorial (que se remite a Vuestra Magestad) para que se sirva mandar pasar los ojos por el) solo refiere quejas de no averse guardado sus leyes, y sus fueros, asi generales de todo el reyno como particulares de algunos lugares, en la resolución de algunos arbitrios añosos al Reyno, y a sus naturales para cuya inteligencia no puede haber mayor probança ni mas relevante, que la información de personas tan graves, con la cual fuerza era antes de pasar adelante a acudir a los reales pies de VM tiene mandado que esto no solo parecio necesario y conveniente al servicio de VM pero se entendio que al Conde de Castrillo, era a quien mas le importaba quedando acaso después del informe mas acrisoladas sus acciones, y mas justificadas asi en lo que pareciese del como por la satisfacción, que el conde sabra dar de si, y de su procedimiento ${ }^{11}$.

Lo que parecía preocupar en mayor medida a los consejeros era el avance sobre las prerrogativas de particulares que tradicionalmente habían tenido un vínculo privilegiado con la Corona, esto posibilitaba el cuestionamiento de la acción del valido frente a su misiva. Como vemos, también aparece el respeto por los fueros y las leyes del reino afectados en la misma gravedad que los particulares. Por la misma causa pedían se revisase la actitud el emisario.

La Cámara de Castilla ponía en duda en algunos pasajes en la actuación del conde, motivo para que se evalúe si su actitud había sido correcta respecto de la conservación de la dignidad de este reino agregado. Los miembros de la Cámara, apoyados en su inmenso "deseo y afán por servir al Rey", dejaban entrever que probablemente había cuestiones por corregir en las resoluciones tomadas por el enviado a Navarra, diciendo que debía actuarse según las leyes de ese reino ${ }^{12}$.

Ahora bien, en la recapitulación de las respuestas que el rey había enviado a la Cámara, queda en evidencia la necesidad que tenía el órgano colegiado de la presencia de García de Avellaneda en Madrid para que sus actos fuesen juzgados,

11 Archivo Histórico Nacional (en adelante AHN), Consejos, Cámara de Castilla, Consultas de gracia, 445: Memorial de la Cámara de Castilla a Felipe IV, 12 de junio de 1630.

12 Ibídem. 
sólo de este modo parecía guardar celo sobre la dignidad de un oficial del rey de tanta estima. Es decir, que para la Cámara era necesario no sobreponer la defensa de un agente de la Monarquía en detrimento de los privilegios de uno de los reinos más antiguos que la componían.

Este criterio expuesto con la mayor prudencia posible resultó contradictorio al criterio que el rey tenía sobre el asunto de Castrillo en Navarra.

Es por ello por lo que en respuesta a este extenso memorial el rey insistía:

Yo estoy mal con las exageraciones y con los exageradores y asi se excusen de aquí adelante y vos el obispo de Granada no cometeréis hacer ninguna consulta a persona de este estilo tan poco a propósito para todo. Proveer informe contra don Garcia de Haro sin orden mia y sin consulta es exceso y con razón debo sentar que se haya hecho y si el consejo de la cámara siente y se siente de que yo me lastime cuando excediere, mal hace y no le del que le he estimado mas que mis suficientes ordenes todos sin haber menester oraciones para hacerlo y asi no habiendo decreto mio ni habiéndome hecho consulta el Consejo ni habiendo oído primero a don Garcia ha sido grande exceso el quererle licitar cuando no se ha hecho con todos como de quienes se, ha quejado también y así el informe que se ha pedido no se hubiere començado no se repasara adelante en el y su cuando estuviere se me enviaran los papeles cerrados y sellados a mis manos sin que se tome noticia de ellos, y sin consulta mia jamas se procedera de esta manera porque seais al paso que se procedio yo estoy informado que quien dio el memorial aun no tenia poder para darle ni se examino si tenia o no cosas muy para procurar executarlas adelante ${ }^{13}$

El rey parecía poner énfasis en la protección de su ministro, pero también en el resguardo de las decisiones que se hacían sobre el reino peninsular; a todo esto, hay que decir que la especial atención en los particulares estaba relacionada con un cambio en el equilibrio de los servidores pecuniarios de la Corona y no en una ruptura con las elites regnícolas, en particular con las de Pamplona.

En ese sentido, Floristán Imízcoz señala que el principal beneficiario de las actividades de Castrillo en Pamplona fue Sancho de Monreal, un acaudalado comerciante de la ciudad. Además de que intervino en la negociación de asientos y donativos para la Corona, adelantó veinte mil ducados en concepto de los oficios renunciables de los tribunales del reino, esto abrió una almoneda masiva de puestos de esta categoría inusitada en Navarra. A pesar de los esfuerzos por obtener beneficios de parte de nuevos asentistas, los beneficiados por Castrillo en Pamplona no alcanzaron a pagar lo que habían pactado, situación que provocó la detención de Monreal, pero también un parcial fracaso de las negociaciones del enviado de Felipe $\mathrm{IV}^{14}$.

Más adelante, hacia 1643, el propio Monreal solicitaba no ser juzgado por un tribunal exterior al reino de Navarra, pedía comparecer ante un tribunal local. Sin embargo, el rey no dudó en nuevamente romper la tradicional política foralista para

\footnotetext{
13 Ibídem.

${ }^{14}$ Floristán, El Reino de Navarra, 186-187.
} 
ordenar a Monreal que se pusiera a disposición del conde de Castrillo en la Corte ${ }^{15}$. El caso de Monreal nos muestra la incidencia que tenían las medidas adoptadas sobre los particulares y sobre todo el tenor social que un recambio amparado en la reforma podía efectuar en una sociedad vinculada a un gobierno territorial.

Esta actividad de intensa transformación no sólo generaba quejas de los miembros de la sociedad política navarra expresados en sus memoriales a Madrid, sino también de quienes representaban al rey en esta comunidad pirenaica, es decir los propios virreyes; es así como el Marqués de Fuentes (1629-1631) manifestaba su desagrado por las consecuencias de estas acciones al conde-duque de Olivares ${ }^{16}$. La preocupación del virrey se originaba en la posibilidad de algunos sujetos de ofrecer sumas importantes a cambio de oficios sin formar parte del sector de los "beneméritos", situación que llevaba a cierto riesgo a Castrillo de confiar en ofrecimientos de dinero imposibles de cumplir por parte de los compradores. Dicha situación también permite leer entre líneas otro de los objetivos de la misión, incrementar el servicio financiero del reino para dar respuesta al gasto producido por la política dinástica de la Monarquía ${ }^{17}$.

A causa de esto, el virrey insistía en la exigüidad de la hacienda navarra y más aún de conservar el lugar de prestigio que tenían ciertas familias. Toda esta situación había motivado la acción del Consejo, ahondando en los ofrecimientos al Rey a cambio de frenar las exigencias de Castrillo sobre las contribuciones que debía aportar el reino, pero la amplitud de poder otorgada al ministro le permitía actuar sobre la diputación e incluso dejaba al virrey como un mero apoyo mientras durase la presencia del conde en Navarra ${ }^{18}$.

A la reforma de la Cámara de Comptos y al recambio entre los servidores financieros de la Corona debemos sumar un tercer factor de los que identificamos como centrales en la actuación de Castrillo, una amplia campaña de venalidad de cargos. Como se ha explicado en los apartados anteriores los cargos vacantes de ciertas instituciones del reino se dieron a Sancho Monreal cambio de sus servicios. Pero este no es el único caso, en otro documento de la Cámara se expresaba:

Primero que estando dispuesto por las dichas leyes libro 1 título 3 de la Recopilación, que los officios de la República hayan de darse por inseculación puso en venta los de

${ }^{15}$ Monreal no dudó en apelar a documentos de la incorporación de Navarra a Castilla para que se hiciera lugar a su reclamo de ser juzgado por tribunales locales. Véase José María Zuaznavar, Ensayo Histórico-Crítico sobre la legislación de Navarra, Libro Segundo (San Sebastián: Imp. Ignacio Ramón Baroja, 1829), 433.

16 Ibídem, 187.

${ }^{17} \mathrm{El}$ profesor Carlos de Carlos Morales ha investigado la incuestionable centralidad del gasto en las políticas económicas de la Monarquía en sus distintas investigaciones. Cuestión que también se convierte en el núcleo explicativo de muchas de las acciones de la Hacienda Real lejanas a una planificación acumulativa y más próximas a haber sido respuestas a la contingencia. Carlos de Carlos Morales, El precio del dinero dinástico: endeudamiento y crisis financieras en la España de los Austrias, 1557-1647 (Madrid: Banco de España, 2016).

18 María del Puy Huici Goñi, La Cámara de Comptos en Navarra en los siglos XVI y XVII (Pamplona: Gobierno de Navarra, 1996), 212-213. 
Regidores y jurados a públicos pregones y en la villa de Olite vendio dos a dos hombres de armas (aunque después se recobraron y en otras partes dio intención que los venderia a gente humilde, y de baja suerte habiendo estado siempre en poder de la gente principal, de lo que resulto que temiendo verse los pueblos en tan triste estado se alargasen, por redimir este trabajo a ofrecer tan grandes sumas, que sino es destruyéndose, no han de poderlas dar ${ }^{19}$.

De este modo se decía que la venalidad de cargos también había generado problemas en las poblaciones navarras, no precisamente porque aquellas se hayan puesto a la venta sino por las transformaciones sociales que esto podía generar. Algunos individuos recientemente enriquecidos podían ahora acceder a oficios integrando a partir de ese momento el servicio de su majestad.

Investigaciones para otros espacios han dado cuenta de cómo la venalidad significaba una profunda transformación social, y de qué manera trastocó los sistemas sociales del honor y del reflejo cosmológico de la sociedad en un orden establecido. La venalidad y sobre todo estas grandes almonedas concentradas en alguna sección del gobierno de la Monarquía o en algún reino en particular generaban una trasformación social importante, se creaba una especie de mérito pecuniario que daba lugar a una relación recíproca entre monarca y compradores, mediada por el dinero. De este modo el significado de los términos "beneficio" y "donativo" también adquiría una connotación pecuniaria, a pesar de que continuaban haciendo referencia a una relación honrosa entre señor y vasallo ${ }^{20}$. De allí la importancia de esta almoneda inmersa en un proceso de mayor escala pero que en comparación produjo resultados similares.

Por último, otro de los esfuerzos que el conde de Castrillo hizo pesar sobre el reino de Navarra estaba íntimamente relacionado con las guarniciones de soldados y la manutención de estos para la defensa de la frontera con Francia. Si bien los años de Felipe III habían significado una relativa tranquilidad por la política pacifista que rey y valido llevaban adelante, la reactivación de la beligerancia de la Monarquía con la llegada de la facción Zúñiga-Olivares llevó a la Monarquía católica-sobre todo para Castilla- a incrementar de manera ulterior su gasto defensivo.

Hacia 1630 la exaltación de la enemistad con el rey cristianísimo y las consecuencias del conflicto por la sucesión de Mantua incrementaron la posibilidad de una guerra con Francia, esto llevó también al ascenso en el tono alarmista de las autoridades navarras en sus misivas a Madrid. Tradicionalmente Navarra había contribuido con hombres y con una especie de alojamiento para las tropas fronterizas, ahora bien, la preocupación señalada significaba un mayor esfuerzo en la contribución para los hombres pirenaicos.

${ }^{19}$ AHN Consejos, Cámara de Castilla, Consultas de gracia 4425: Memorial visto en la Cámara de Castilla.

${ }^{20}$ Véase Francisco Andújar Castillo, "Los contratos de venta de empleos en la España del Antiguo Régimen", en El poder del dinero: ventas de cargos y honores en la España del Antiguo Régimen, ed. Francisco Andújar Castillo y María del Mar Felices de la Fuente (Madrid: Ed. Biblioteca Nueva, 2011), 9-32. 
Así por ejemplo la villa de Cascante reclamaba por la despoblación y el descontento que el alojamiento de tropas había generado sobre su jurisdicción, situación que no había afectado a los hidalgos "sino a los más desfavorecidos", esto iba en detrimento de los productores ganaderos de la zona y aún más gravosas eran las facultades de recaudación que Castrillo había dado sobre estas personas ${ }^{21}$.

Pamplona también se declaraba afectada en la misma forma que aquella localidad meridional del reino. En consecuencia, los representantes de la ciudad resumían sus reclamos considerándola incapaz de aportar si quiera cien hombres para la defensa de la frontera, para ello apelaban a la pobreza del reino.

Sin embargo, este no era el único discurso al que referían en sus reclamaciones, también hacían presentes hechos de la historia del reino para recordar a Felipe IV que en el pasado la ciudad había servido con 180 hombres y Navarra con 400. También argumentaban que:

Que esta consideración y las demás que debieron ocurrir a la prudencia de la Magestad del señor Rey don Felipe II le obligaron a no permitir que en Navarra se pidiese donativo cuando se pidió en los Reynos de Castilla y pues todo lo referido es cierto y a atención de VM a la defensa de sus Reynos tan conocida como loable y la frontera de Navarra la principal muralla de España ${ }^{22}$.

A raíz de todos estos problemas se pedía al monarca que dejase sin efecto todos los cambios y ordenanzas dadas por el conde de Castrillo en Navarra. Asimismo, se observa que algunos servidores financieros de la Corona fueron beneficiados con prerrogativas en el interior del reino. Por ejemplo, por la cesión de los puertos secos, el señor de Bértiz recibió la alcaldía de la ciudad de Estella ${ }^{23}$.

De este modo, queda en evidencia que el rechazo a las actividades reformistas de Castrillo no era unánime, en ese sentido el Depositario General del Reino fue uno de sus principales colaboradores ${ }^{24}$. En síntesis, hasta ahora se han observado cuáles han sido las consecuencias inmediatas de la acción del conde de Castrillo y la respuesta de quienes se vieron perjudicados por la reforma que se pretendía realizar.

En adelante analizaremos otro aspecto vinculado a la representación política del reino en la Monarquía, así como a las reapropiaciones de los saberes políticos al momento de argumentar una postura.

\section{TRASTOCAR EL REINO}

Las reformas hacendísticas que Castrillo propuso en Navarra dieron lugar a que una multiplicidad de discursos sobre el estatus del reino en el conjunto de la Monarquía Hispana resurgiese. Este tópico aparece constantemente en los

\footnotetext{
${ }^{21}$ AHN, Consejos, Cámara de Castilla, Consultas de gracia, 445.

22 AHN, Consejos, Cámara de Castilla, Consultas de gracia, 445: Carta del Reino de Navarra a Felipe IV.

${ }^{23}$ Ostolaza Elizondo, “La Hacienda...”, p. 148-149.

${ }^{24}$ Ibídem.
} 
documentos emanados por una parte de los afectados por las transformaciones entre los órganos de gobierno del reino. Por ejemplo, en el destacado tono alarmista expresado en las discusiones de los consejos, en los cuales se observa también un fuerte contenido político-integrista.

En ese sentido, doctrinas políticas del momento relucen en la documentación analizada en conexión con las transformaciones impulsadas por Olivares en la primera etapa de su valimiento. Las doctrinas agregativas, conservadoras y articuladoras de la Monarquía Católica fueron entonces el centro de los argumentos para plantear el impacto negativo que tuvieron las novedades de 1629 y 1630.

De este modo, el Consejo de Cámara evaluaba la posibilidad de un daño al derecho consuetudinario que la corona de Navarra había obtenido por su servicio a la dinastía:

Aquel señor es un reino agregado a este en tiempo del señor Rey Católico, no por derecho de sangre, ni por fuerza de las armas, sino por servicio que esta corona hizo a la Iglesia y a la oposición del Rey don Juan a ella, y la entrega voluntaria de la mayor parte de aquellos vasallos, y otras razones que refieren las historias, y se tuvo por una de las cosas mayores y más importantes, y felices que subcedieron en aquellos tiempos con ser inumerables, para conservación y guarda de estos reinos ${ }^{25}$.

En efecto, se observa que la acción transformadora de la Monarquía en el reino podía verse como una acción punitiva. Asimismo, se reutilizaba la memoria para recordar a Felipe IV la forma por la que estos reinos habían llegado a formar parte de su herencia.

Al mencionar la agregación del reino, el Consejo de Cámara obviaba que la anexión navarra se había producido por conquista, en reemplazo a ello se apelaba a la agregación por servicio a la Iglesia, es decir por donación de la Santa Sede. Estas dos situaciones planteaban una diferencia sustancial en el tratamiento que se debía y podía tener para con el reino incorporado ${ }^{26}$.

Conquistada por Fernando el Católico a principios del siglo XVI, la corona de Navarra fue un caso excepcional en un contexto en el que la vía matrimonial era la privilegiada para la formación de composiciones políticas ${ }^{27}$. Sin embargo, la transición dinástica no solo fue un paso hacia la dinastía de Trastámara; superados los gajes de la conquista castellana el reino pirenaico pasó, junto con un gran número de territorios, a los dominios heredados por la casa de Habsburgo.

Tengamos en cuenta que, como parte de las estrategias adaptativas propias de su época, la Monarquía Hispana se constituyó a partir de un conjunto de métodos

${ }^{25}$ AHN, Consejos, Cámara de Castilla, Consultas de gracia, 442.

${ }^{26} \mathrm{El}$ profesor Gil Pujol ha realizado una clara explicación para el caso de las Indias, que bien se puede aplicar al caso navarro debido a que se basa en principios jurídicos adoptados en el conjunto de la Monarquía. Xavier Gil Pujol, La fábrica de la Monarquía. Traza y conservación de la Monarquía de España de los Reyes Católicos y los Austrias (Madrid: Real Academia de la Historia, 2016), 226-228.

27 Alfredo Floristán Imízcoz, "Conquistas y uniones en la Europa del Renacimiento: El reino de Navarra”, Indagación: Revista de Historia y Arte 4 (1994): 75-88 (Especialmente página 78). 
agregativos. Esos dispositivos se usaron como estrategia para reunir a esa variedad de territorios que habían heredado ${ }^{28}$. De este modo, el reino de Navarra pasaba a ser un miembro más de ese cuerpo político.

Sin embargo, no se puede negar que a pesar del respeto por sus fueros este reino presentaba algunas anomalías respecto de los demás pertenecientes al rey católico. En principio debía su representación en Madrid a la Cámara de Castilla y su consejo regnícola tenía sede en Pamplona bajo la denominación de Consejo Real de Navarra.

Sin embargo, este proceso no significó que la tradición consuetudinaria de oficios locales se perdiera y en este punto sí se asimiló a otros dominios como Aragón, Borgoña o Vizcaya. De hecho, al momento que los demás reinos presentaban sus fueros y privilegios a Carlos $\mathrm{V}$ (aproximadamente en la década de 1520), el reino de Navarra también presentó una versión del texto del Fuero en $1528^{29}$. A eso sumamos, que la definición de competencias del Consejo Real navarro también se clarificó a lo largo del siglo XVI como órgano superior de apelación y como el ámbito colegiado que acompañaría la gestión de los virreyes en función de los intereses locales.

Así es que cuando nos encontramos hacia 1630 con la preocupación de la Cámara de Castilla por la falta de cuidado que presumiblemente tuvo el conde de Castrillo, en realidad hay un cuestionamiento por la forma de integración de la Monarquía.

Ahora bien, es cierto también que las medidas encaminadas a una mejor recaudación en el reino de Navarra no tenían la intención de corromper el vínculo de reciprocidad establecido en su momento. De hecho, a lo largo de la década de 1620 las acciones de Felipe IV y Olivares no habían tenido otro fin que el financiamiento de la guerra para sostener la reputación de la dinastía.

De modo que no podemos leer la intervención de Castrillo, hasta ese momento claro partidario del valido, en el marco de un proceso de intromisión de la Monarquía en los asuntos regnícolas sino en una solución para dar cabida al gasto en la guerra. Desde los inicios del reinado las actividades militares habían aumentado el gasto dinástico, la década ya mencionada está plagada de intentos por obtener el suficiente crédito para permitir tomar más deuda ante la suba de los gastos por los conflictos bohemio y en los Países Bajos ${ }^{30}$.

\footnotetext{
${ }^{28}$ Pujol explica las formas de configuración de la Monarquía Hispana, no como una excepción a la regla europea del momento sino como una adaptación a la compleja realidad que su contexto imponía. Gil Pujol, La fábrica de la monarquía, 22.

${ }^{29}$ Jon Arrieta Alberdi, "Martín de Azpilicueta como fuente doctrinal y testimonio personal para el análisis y valoración de la integración de Navarra en la Monarquía de los Austrias", en La Diadema del Rey. Vizcaya, Navarra, Aragón y Cerdeña en la Monarquía de España (Siglos XVI-XVIII), ed., Jon Arrieta Alberdi y Xavier Gil Pujol (Bilbao: Universidad del País Vasco, 2017), 388.

${ }^{30} \mathrm{El}$ profesor Carlos de Carlos Morales ha investigado los vaivenes que hay en la economía de la Hacienda Real cuando las estrategias de utilización de juros y las jugadas con la moneda de vellón perdieron eficacia. También por una progresiva pérdida de confianza respecto del pago de los juros lo cual inevitablemente terminó en un proceso deflacionario para los mismos. De Carlos Morales, El precio del dinero dinástico, 168-180.
} 
En efecto, la intervención de Castrillo se encuentra entre este conjunto de medidas económicas que, según la política de los primeros años del reinado de Felipe IV, permitiría tomar más deuda a la Monarquía para ser transformada en gasto militar. Con lo cual la elección del conde de Castrillo tampoco resulta un fenómeno aleatorio ni único. A lo largo de la década de 1620 se habían convocado "especialistas" para atender a las necesidades financieras de la Corona.

Más adelante, en 1622 una primera Junta de Comercio, convocada para romper la caída comercial hispana frente a la competencia de las Provincias Unidas, estuvo presidida por el marqués de Montesclaros. Debido a su actuación como virrey en Nueva España y Perú conocía los efectos que una competencia comercial como la holandesa podía causar a los vínculos pecuniarios entre la Península y América ${ }^{31}$. Asimismo, al presentarse la Unión de Armas como un proyecto hacendístico para todos los dominios de Felipe IV, su ejecución en los órganos hacendísticos de los Países Bajos estuvo a cargo del marqués de Leganés. Este titulado presentó en 1627 las transformaciones previstas para la contribución general que todos los reinos debían realizar, fue el encargado de llevar la versión flamenca de la famosa Unión ${ }^{32}$. Según Elliot su participación en el ejército de Flandes desde 1600 así como su función como oficial de la casa del archiduque Alberto motivó su elección ${ }^{33}$.

Ahora bien, Leganés no sólo era un miembro experimentado de la política de la Monarquía Católica sino también guardaba un vínculo muy especial con Olivares, perteneciente a una rama de la familia de los Guzmán y valedor del patronímico Phelipez en honor al rey, fue siempre candidato a las mercedes que el valido podía conseguir de parte de Felipe IV $^{34}$.

En perspectiva comparada, el conde de Castrillo había transitado ya un considerable camino político y académico, desde sus tiempos de colegial de Cuenca hasta su entrada en Valladolid y el Consejo de Órdenes. Además de su vínculo clientelar con Olivares corría con otras ventajas ya mencionadas con anterioridad, su suegro don Bernardino de Avellaneda se había desempeñado como virrey de Navarra. Por ende, las relaciones sociales establecidas en su momento habían sido heredadas por Avellaneda y Haro a través de su esposa, vínculo que se reafirmó en el casamiento de su hija Inés con el primogénito de la casa Mauleón y Navarra.

De este modo también podemos esbozar alguna caracterización de los servidores de la primera etapa olivarista. Elegidos tanto por su trayectoria política y formativa, así como por el vínculo afectivo o familiar que éstos habían consolidado anteriormente, la facción olivarista fue más un núcleo de servidores fieles que en su momento funcionó para solventar las necesidades de omnipresencia del valido. Por

\footnotetext{
31 Pere Molas Ribalta, "Instituciones y comercio en la España de Olivares", Studia Histórica: Historia Moderna 5 (1987): 91-98.

32 Alicia Esteban Estríngana, "Guerra y redistribución de cargas defensivas: la Unión de Armas en los Países Bajos", Cuadernos de Historia Moderna 27 (2002): 49-98.

${ }^{33}$ John Elliott, El Conde-Duque de Olivares, El político en una época de decadencia (Barcelona: Crítica, 1990), 280.

34 Para un panorama general de la vida de Leganés. Francisco Arroyo Martín, "El marqués de Leganés. Apuntes Biográficos”, Espacio, Tiempo, y Forma, Ha. Moderna 15 (2002): 145-185.
} 
ello no podemos afirmar que se trató de personas sin ninguna capacidad de gobierno, sino analizar su elección como delegados como un fenómeno multicausal. En este marco el conde de Castrillo pareció cumplir con los requisitos para ser uno de los ejecutores de la política monárquica a finales de 1620.

Dicho esto, podemos afirmar que el objetivo de la misión de Castrillo en Navarra no estaba destinada a afectar la integridad de este reino como un ente con jurisdicción propia y fueros antiguos, sino que correspondió a una acción hacendística llevada adelante en distintos territorios por la misma época.

Ahora bien, tampoco es desdeñable el recurso discursivo que los consejeros del rey utilizaron para advertir - o exagerar- las consecuencias que podían tener las decisiones llevadas adelante por el conde y avaladas por el rey.

Asimismo, las cautelosas críticas elevadas por la Cámara de Castilla a Felipe IV sobre el accionar de Castrillo expresadas en frases como "no seria justo ni conveniente al servicio de Dios y de $\mathrm{V}$, y bien de aquel Reino, que se usase de un medio tan extraordinario, al consejo le parece en esta parte, que no es bien usar de $\mathrm{el}^{35}$ " en la que se hace alusión a la exageración en las reformas llevadas adelante en el Reino. También en expresiones como "es el príncipe deudor de oy a sus vasallos todas las quejas que dieren, hacerles justicia dar satisfacción publica a todos" 36 resaltando que el favoritismo o la protección del conde no podían ser un impedimento para el normal ejercicio de la justicia real. Todo parecía indicar que por lo menos en su mayor proporción dicho órgano polisinodial giraba en torno a la oposición de algunas medidas hacendísticas llevadas adelante en el reino pirenaico ${ }^{37}$.

La reacción de Felipe IV tenía un fuerte contenido apologético sobre el servicio realizado por Castrillo en Navarra para beneficio de la Real Hacienda. Al punto que criticaba el proceder de la Cámara, cuyos miembros habían actuado en ausencia de García de Avellaneda y Haro y sin pedido del monarca.

Esta respuesta no sólo nos permite identificar una reafirmación de las medidas implementadas por el enviado de la corte a Navarra sino también una especie de proceso de afirmación del vínculo establecido entre el monarca y su servidor. En esta relación recíproca que usualmente los monarcas establecían con sus cortesanos en el Antiguo Régimen también podemos establecer historizaciones o periodizaciones.

En ese marco, este momento tiene un beneficio trascendental en la carrera política del conde de Castrillo: se trata de un momento de consolidación de un poder personal frente al rey. Un vínculo que parece desprenderse de la mediación del valido la cual fue fundamental en los primeros años de servicio de García de Avellaneda y Haro.

Esta hipótesis aquí planteada no es una conclusión cerrada dado que veremos una actuación de nuestro protagonista cada vez más extendida en los distintos

\footnotetext{
35 AHN, Consejos, Consultas de Gracia, Cámara de Castilla 4425.

${ }^{36}$ Ibídem.

${ }^{37}$ Ibídem.
} 
espacios de gobierno, así como en su relación con otros actores políticos de importancia.

Con lo cual no solo hablamos de una consolidación del poder del cortesano sino también de la creación de un poder relacional multilateral, lo que también nos permitirá explicar luego el desapego que sintió hacia su original patrono tras los sucesos de 1640 y la estrategia política de asimilación de un nuevo contexto a partir de la década del 40.

\section{CONSIDERACIONES FINALES}

Toda la trama explicativa de este artículo se basa en el análisis que se desprenden de la exploración de la documentación del bienio 1629-1630 pero que se proyectan en un largo tiempo posterior, son entonces el eje articulador que nos permite continuar con la explicación de la carrera política de García de Avellaneda y Haro.

Por otro lado, el contexto de las reformas de Navarra es además un momento de cuestionamiento de la autoridad virreinal, no por parte de las elites locales de los reinos sino en este caso por parte de la propia Monarquía.

No olvidemos los cuadros políticos del sistema de consejos junto con la aplicación del sistema virreinal habían sido el instrumento por excelencia mediante el cual la Monarquía Hispana logró articular territorios tan disimiles en torno a la dinastía de los Austria y sobre todo a través de su vinculación con la Corte de Madrid $^{38}$. En ese aspecto, el profesor Rivero Rodríguez ha advertido que durante el reinado de Felipe IV se produce una degradación de ese poder virreinal identificado en sus orígenes con el desdoblamiento de la persona del rey en sus lugartenientes ${ }^{39}$.

En ese sentido, el poder cuasi plenipotenciario ejercido por Castrillo en Navarra motivó las quejas del virrey provocando una disputa inusitada, si bien como hemos dicho se trató de una intervención enmarcada en una época de misiones a los reinos encargadas a los hombres del rey. No deja de ser un proceso de atenuación o por lo menos de yuxtaposición de dignidades políticas en un mismo espacio político, por lo todo parece indicar que en principio las quejas del Consejo de Cámara también guardaban recelo por la transformación moral que se producía en torno a antiguos mecanismos de poder, tan antiguos y tradicionales como la misma Monarquía.

Por último, se han observado dos ideas centrales fruto de la investigación. Por un lado, que las medidas políticas aplicadas en Navarra son importantes porque se transforman en una lente privilegiada para observar el conocimiento de sus actores respecto de las tradiciones políticas mediante las cuales se había incorporado a la Monarquía. Además, permite observar la diversidad de formas que adoptaba el

\footnotetext{
${ }^{38}$ Manuel Rivero Rodríguez, "De la separación de la unión dinástica: la corona de Aragón entre 1504 y 1516", en La Corte de Carlos V, Vol. 1, ed. J. Martínez Millán y C. de Carlos Morales (Madrid: Sociedad estatal para la conmemoración de los centenarios de Felipe II y Carlos V, 2000), 73-105.

${ }^{39}$ Manuel Rivero Rodríguez, "La reconstrucción de la Monarquía Hispánica: la nueva relación con los reinos (1648-1680)", Revista Escuela de Historia 12 (2013).
} 
conglomerado político de los Austrias en las geografías y sociedades a las que debía gobernar. 


\section{REFERENCIAS BIBLIOGRÁFICAS}

Francisco Andújar Castillo, "Los contratos de venta de empleos en la España del Antiguo Régimen", en Elpoder del dinero: ventas de cargos y honores en la España del Antiguo Régimen, ed. Francisco Andújar Castillo y María del Mar Felices de la Fuente (Madrid: Ed. Biblioteca Nueva, 2011), 9-32.

Jon Arrieta Alberdi, "Martín de Azpilcueta como fuente doctrinal y testimonio personal para el análisis y valoración de la integración de Navarra en la Monarquía de los Austrias", en La Diadema del Rey. Vizcaya, Navarra, Aragón y Cerdeña en la Monarquía de España (Siglos XVI- XVIII), ed., Jon Arrieta Alberdi y Xavier Gil Pujol (Bilbao: Universidad del País Vasco, 2017), 388.

Francisco Arroyo Martín., "El marqués de Leganés. Apuntes Biográficos”, Espacio, Tiempo, y Forma, Ha. Moderna 15 (2002): 145-185.

Carlos de Carlos Morales, "Olivares y los banqueros de Felipe IV. La crisis financiera de 1627”, Libros de la Corte.es 2 (2010): 9-15.

Carlos de Carlos Morales, El precio del dinero dinástico: endendamiento y crisis financieras en la España de los Austrias, 1557-1647, Vol. 1 (Madrid: Banco de España, 2016)

Antonio Domínguez Ortiz, Política y Hacienda de Felipe IV, (Madrid: Editorial de Derecho Financiero, 1960), 3-17.

John Elliott, El Conde- Duque de Olivares, El político en una época de decadencia, (Barcelona: Crítica, 1990), 280.

Alicia Esteban Estríngana, "Guerra y redistribución de cargas defensivas: la Unión de Armas en los Países Bajos”, Cuadernos de Historia Moderna 27 (2002): 49-98.

Alfredo Floristan Imízcoz, "Conquistas y uniones en le Europa del Renacimiento: El reino de Navarra", Indagación: Revista de Historia y Arte 4 (1994): 75-88.

Alfredo Floristán Imízcoz, El Reino de Navarra y la conformación política de España (15121841), (Madrid: Akal, 2014), 5-20.

Xavier Gil Pujol, La fábrica de la Monarquía. Traza y conservación de la Monarquía de España de los Reyes Católicos y los Austrias, (Madrid: Real Academia de la Historia, 2016).

María del Puy Huici Goñi, La Cámara de Comptos en Navarra en los siglos XVI y XVII, (Pamplona: Gobierno de Navarra, 1996). 
Pere Molas Ribalta, "Instituciones y comercio en la España de Olivares", Studia Histórica: Historia Moderna 5 (1987): 91-98.

María Narbona Cárceles, La Corte de Carlos III el noble, Rey de Navarra, (Pamplona: EUNSA, 2006).

María Isabel Ostolaza Elizondo, "La Hacienda Real de Navarra durante la etapa de los Austrias", Principe de Viana, 240 (2007), 225-262.

Manuel Rivero Rodríguez, "De la separación de la unión dinástica: la corona de Aragón entre 1504 y 1516", en La Corte de Carlos V, Vol. 1, ed. J. Martínez Millán y C. de Carlos Morales, (Madrid: Sociedad estatal para la conmemoración de los centenarios de Felipe II y Carlos V, 2000), 73-105.

Manuel Rivero Rodríguez, La Edad de Oro de los virreyes. El virreinato en la Monarquía Hispánica durante los siglos XVI y XVII, (Madrid: Akal, 2011).

Manuel Rivero Rodríguez, "La reconstrucción de la Monarquía Hispánica: la nueva relación con los reinos (1648-1680)", Revista Escuela de Historia 12 (2013).

José María Zuaznavar, Ensayo Histórico-Crítico sobre la legislación de Navarra, Libro Segundo, (San Sebastián: Imp. Ignacio Ramón Baroja, 1829).

Recibido: 14 de agosto de 2018

Aprobado: 25 de marzo de 2019 